\title{
Gas chromatography of indium in macroscopic and carrier-free amounts using quartz and gold as stationary phases
}

\author{
By A. Serov ${ }^{1,2}$, R. Eichler ${ }^{1,2, *}$, R. Dressler ${ }^{1}$, D. Piguet ${ }^{1}$, A. Türler ${ }^{1,2}$, A. Vögele ${ }^{1}$, D. Wittwer ${ }^{1,2}$ and H. W. Gäggeler ${ }^{1,2}$ \\ ${ }^{1}$ Laboratory for Radiochemistry and Environmental Chemistry, Paul Scherrer Institute, 5232 Villigen, Switzerland \\ 2 Departement for Chemistry and Biochemistry, University Bern, 3012 Bern, Switzerland
}

(Received March 15, 2010; accepted in final form September 6, 2010)

Indium / Indium hydroxide / Adsorption /

Thermochromatography / Sublimation

Summary. The chemical investigation of E113 is likely to become soon feasible. The determination of chemical properties of carrier-free amounts of the lighter homologues of element 113, especially indium and thallium, allows designing experimental set-ups and selecting experimental conditions suitable for performing these studies. Here, we present investigations of the interaction of indium species with quartz and gold surfaces. Deposition temperatures as well as enthalpies of adsorption were determined for indium $T_{\text {dep }}=739 \pm 20^{\circ} \mathrm{C}$ $\left(-\Delta H_{\text {ads }}(\mathrm{In})=227 \pm 10 \mathrm{~kJ} \mathrm{~mol}^{-1}\right)$ and for indium hydroxide $T_{\text {dep }}=250 \pm 20^{\circ} \mathrm{C} \quad\left(-\Delta H_{\text {ads }}(\mathrm{InOH})=124 \pm 10 \mathrm{~kJ} \mathrm{~mol}^{-1}\right)$ respectively, on quartz. In case of adsorption of indium on a gold surface only a lower limit of the deposition temperature was established $T_{\text {dep }}>980^{\circ} \mathrm{C}\left(-\Delta H_{\text {ads }}(\right.$ In $) \geq 315 \pm$ $10 \mathrm{~kJ} \mathrm{~mol}^{-1}$ ). Investigations of macroscopic amounts of indium in thermosublimation experiments at similar experimental conditions were instrumental to establish a tentative speciation of the observed indium species.

\section{Introduction}

Transactinide elements (the elements having $Z>103$ ), artificially produced in heavy-ion-induced nuclear fusion reactions, have been known for several decades. During this period a significant effort improving production techniques (accelerators, ion sources, new target-projectile combinations, new target setups) as well as developing new detection systems allowed to synthesize and to identify new elements with $Z$ up to 118 [1]. Physical experiments revealed these elements being characterized typically by short half-lives and low production rates on a one-atom-at-a-time level. These facts significantly complicate the determination of chemical properties of transactinides. It should be mentioned that from the variety of available chemical methods only few are suitable for the investigation of the chemical behavior of transactinides. Nowadays, mainly techniques based on the following three separation methods are applied: 1) gas adsorption thermochromatography or isothermal chromatography, 2) liquid phase ion-exchange and extraction chromatography, and 3 ) electrochemical deposition (see for review $[2,3]$ ).

\footnotetext{
*Author for correspondence (E-mail: robert.eichler@psi.ch).
}

Since the 1960's several successful experiments with elements Rf, $\mathrm{Db}, \mathrm{Sg}, \mathrm{Bh}, \mathrm{Hs}$, and $\mathrm{Cn}$ have been performed [4-14]. The given references represent an important subset of all available experiments on the chemistry of these elements. A comprehensive overview can be found in references [2] and [3]. The deduced chemical properties were mostly in good agreement with the hypothesis that the transactinide element should behave chemically similar to its lighter homologues in the corresponding group of the periodic table. Recently, first experiments with element 114 have been performed $[15,16]$. For a successful design of chemical experiments with transactinides the chemical investigations of their lighter homologues in carrier-free amounts were shown to be instrumental. Currently, experiments with element 113 are under development. We report here on gas-phase adsorption thermochromatographic investigations of the interaction of carrier-free ${ }^{113 \mathrm{~m}}$ In as a homologue of element 113 with quartz and gold surfaces. First thermochromatography experiments with carrier-free amounts of indium in quartz columns [17] revealed a deposition pattern with one maximum at temperatures of $320{ }^{\circ} \mathrm{C}$ which was attributed to volatile metallic indium. We show here new data on the deposition behavior of elemental indium and its hydroxide. Carrier-added experiments were performed for comparison. The microscopic model of gas adsorption chromatography, implemented into a Monte-Carlo simulation code [18], yielded the standard adsorption enthalpy at zero surface coverage $\left(\Delta H_{\text {ads }}\right)$ of ${ }^{113 \mathrm{~m}} \mathrm{In}$ species on both surfaces. From the experiments with added indium carrier sublimation data could be evaluated using the thermosublimation approach [19]. As summarized in Table 1 literature data related to the formation and to the volatility of chemical species existing in the In-O- $\mathrm{H}_{2} \mathrm{O}$ system are very scarce. These literature data (Table 1 ) were used for the identification of metallic indium. No corresponding literature data are available for $\mathrm{InOH}$. Therefore, a tentative speciation was made from analogy assumptions in group 13 and new sublimation data have been deduced.

\section{Experimental}

\section{$2.1^{113 m}$ In production}

A tracer for indium was prepared using the ${ }^{113} \mathrm{Sn}\left(T_{1 / 2}=\right.$ $115 \mathrm{~d}) /{ }^{113 \mathrm{~m}} \mathrm{In}\left(T_{1 / 2}=99 \mathrm{~min}\right)$ generator system [24]. For 
Table 1. Thermodynamics data for potentially volatile indium species in different carrier gases (taken from [20] if not indicated otherwise).

\begin{tabular}{|c|c|c|c|c|c|}
\hline Species & $\begin{array}{l}\text { Melting } \\
\text { point, }{ }^{\circ} \mathrm{C}\end{array}$ & $\begin{array}{l}\text { Boiling } \\
\text { point, }{ }^{\circ} \mathrm{C}\end{array}$ & $\begin{array}{c}\Delta H_{\text {subl }} \\
\mathrm{kJ} \mathrm{mol}^{-1}\end{array}$ & $\begin{array}{c}D_{\mathrm{e}} \\
\mathrm{kJ} \mathrm{mol}^{-1}\end{array}$ & $\begin{array}{c}\Delta H_{\mathrm{f}}^{298} \\
\mathrm{~kJ} \mathrm{~mol}^{-1}\end{array}$ \\
\hline $\operatorname{In}(\mathrm{s})$ & $156.6[21]$ & 2072 [21] & $\begin{array}{l}243.3[21] \\
242.6[22]\end{array}$ & 0 & 0 \\
\hline $\mathrm{In}_{2}(\mathrm{~g})$ & & & $\begin{array}{l}380.9[21] \\
360 \pm 20^{a}\end{array}$ & 24 & 392 \\
\hline $\mathrm{In}_{2} \mathrm{O}_{3}(\mathrm{~s})$ & 1910 & $>3300$ & 531 & & $\begin{array}{c}-925.3 \\
-925.7[22] \\
-925.8[21]\end{array}$ \\
\hline $\mathrm{In}_{2} \mathrm{O}(\mathrm{g})$ & & & & 774.04 & $\begin{array}{c}-55.0 \\
-65.7[22]\end{array}$ \\
\hline $\mathrm{In}_{2} \mathrm{O}(\mathrm{s})$ & 325 & $>700$ & & & \\
\hline $\mathrm{InO}(\mathrm{s})$ & & & & & 387.0 [21] \\
\hline $\mathrm{InO}(\mathrm{g})$ & & & & 76 & $\begin{array}{c}167.3 \\
(387.0)\end{array}$ \\
\hline $\mathrm{InOH}(\mathrm{g})$ & & & $160 \pm 15^{a}$ & & $\begin{array}{c}-112.968 \\
\Delta H_{\mathrm{f}}^{0}= \\
-104.65[23]\end{array}$ \\
\hline $\mathrm{In}(\mathrm{OH})_{3}(\mathrm{~s})$ & 340 & & & & $\begin{array}{c}-760.023 \\
\Delta H_{\mathrm{f}}^{0}= \\
-552.6[23]\end{array}$ \\
\hline $\mathrm{In}(\mathrm{OH})_{2}(\mathrm{~g})$ & & & & & $\begin{array}{c}\Delta H_{\mathrm{f}}^{0}= \\
-243.4[23]\end{array}$ \\
\hline
\end{tabular}

a: This work.

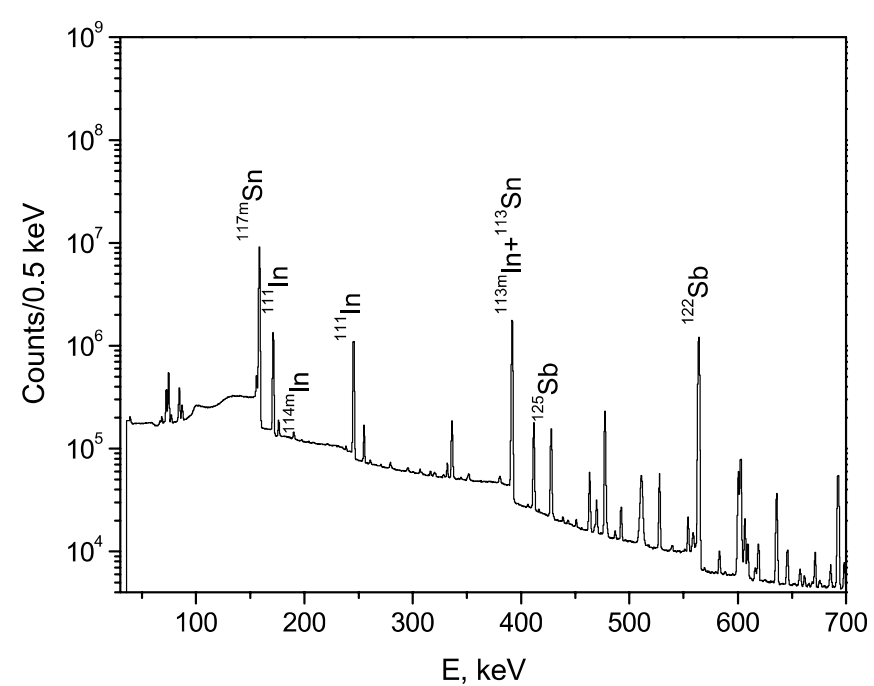

Fig. 1. Gamma spectrum of neutron irradiated natural tin.

that purpose $0.5 \mathrm{~g}$ of ${ }^{\text {nat }} \mathrm{Sn}(99.9995 \%$ purity, Fluka) was irradiated at the neutron activation facility (SINQ-NAA) at the Paul Scherrer Institute for $2 \mathrm{~h}$ at a neutron flux of $10^{13} \mathrm{~s}^{-1} \mathrm{~cm}^{-2}$. The analysis of the gamma spectra from neutron irradiated ${ }^{\text {nat }} \mathrm{Sn}$ shows that the mainly produced isotopes are ${ }^{113} \mathrm{Sn},{ }^{113 \mathrm{~m}} \mathrm{In},{ }^{111} \mathrm{In},{ }^{114 \mathrm{~m}} \mathrm{In},{ }^{117 \mathrm{~m}} \mathrm{Sn},{ }^{122} \mathrm{Sb}$, and ${ }^{125} \mathrm{Sb}$ (Fig. 1). The presence of ${ }^{111} \mathrm{In}$ and ${ }^{122} \mathrm{Sb}$ can be explained by macroscopic amounts of indium and antimony contaminations in the metallic tin sample. The amount of antimony in the tin was estimated to about $100 \mathrm{ppm}$. It was found by neutron activation analysis that the upper limit of macroamounts of indium in the original tin sample is about $10 \mathrm{ppm}$.

\subsection{Sample preparation for thermosublimatography}

The irradiated sample was dissolved in a minimum amount of $\mathrm{HCl}_{\text {conc }}$. Several milliliters of $30 \% \mathrm{H}_{2} \mathrm{O}_{2}$ were added to oxidize present $\mathrm{Sn}^{2+}$ and the contamination $\mathrm{Sb}^{3+}$. The obtained solution containing $\mathrm{Sn}^{4+}$ and $\mathrm{Sb}^{5+}$ was deposited onto a column packed with anion-exchange resin (Dowex $1 \times 8$ 200-400 mesh). Using $1 \mathrm{M} \mathrm{HCl}$ as an eluent, the separation of ${ }^{113 \mathrm{~m}} \mathrm{In}$ from its parent ${ }^{113} \mathrm{Sn}$ and from the antimony contamination was achieved. The separation was monitored by gamma spectroscopy. The first eluted fractions contained the macroscopic amounts of indium (several micrograms) marked with ${ }^{114 \mathrm{~m}} \mathrm{In}$ and ${ }^{113 \mathrm{~m}} \mathrm{In}$. These fractions were transformed into the oxide by addition of concentrated $\mathrm{HNO}_{3}$, followed by evaporation to dryness and by a final heating to $500{ }^{\circ} \mathrm{C}$ in air. Finally, $10 \mathrm{mg}$ of natural indium metal were added. This controlled carrier addition was needed because the total indium amount has to be known fairly well for the data analysis from thermosublimatograpy experiments. The indium oxide and indium metal mixture were transferred into a small tantalum tube and served for the thermosublimatography experiments (see Sects. 2.4 and 3.1.1). For the experiments with oxidizing carrier gases the indium oxide was deposited on a quartz wool plug, which served directly as a source for the experiments. The $10 \mathrm{mg}$ of natural indium metal were added directly into the column prior to the experiments. 


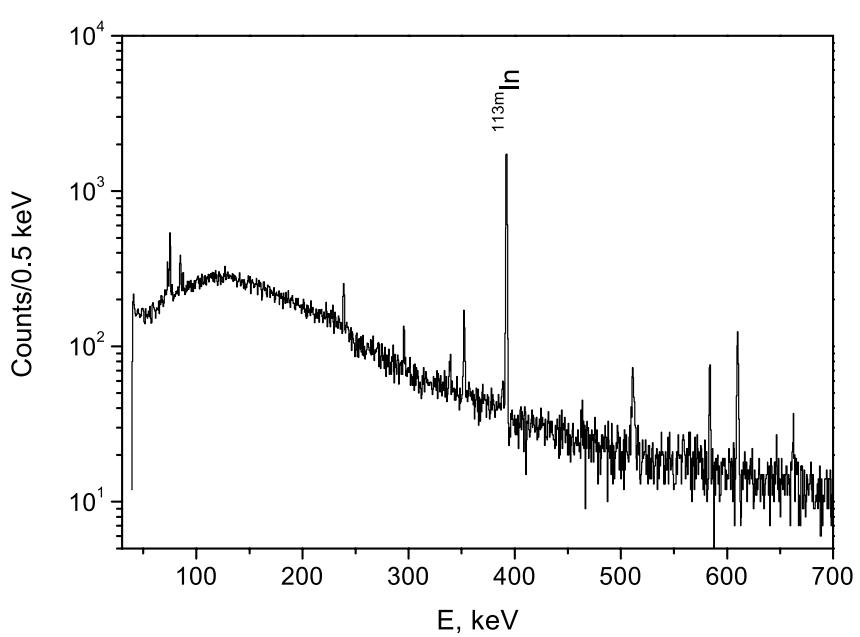

Fig. 2. Gamma spectrum of an eluted ${ }^{113 \mathrm{~m}} \mathrm{In}$ sample.

\subsection{Sample preparation for thermochromatography}

Method 1

The column with the deposited irradiated tin sample was carefully washed with $1 \mathrm{M} \mathrm{HCl}$, until full elimination of ${ }^{114 \mathrm{~m}} \mathrm{In}$ from the generator. The absence of ${ }^{114 \mathrm{~m}} \mathrm{In}$ in the gamma spectra of the final eluates was taken as an indication of the full separation of macroscopic amounts of indium from the tin. Based on the gamma spectra of the eluate (Fig. 2) the main remaining activity can be assigned to ${ }^{113 \mathrm{~m}} \mathrm{In}$, as the permanently produced decay daughter of ${ }^{113} \mathrm{Sn}$. No gamma lines from ${ }^{117 \mathrm{~m}} \mathrm{Sn}$ or ${ }^{122} \mathrm{Sb}$ were observed anymore, confirming also the efficient separation of antimony from indium. The separation factor based on comparison of the activity of ${ }^{114 \mathrm{~m}} \mathrm{In}$ (indicator for macroamounts of indium) in the irradiated sample and in the eluate can be estimated as $>10^{5}$. The eluted carrier-free ${ }^{113 \mathrm{~m}} \mathrm{InCl}_{3}$ was transformed into oxide by addition of concentrated $\mathrm{HNO}_{3}$, followed by evaporation to dryness and by heating to $500{ }^{\circ} \mathrm{C}$ in air. Subsequently, the sample was transferred into a small tantalum tube serving directly as a source for thermochromatographic investigations. For the experiments with oxidizing carrier gases the sample was dried on quartz wool and was used without tantalum directly as a source.

\section{Method 2}

The irradiated tin sample was heated in a constant flow of dry hydrogen (flow rate $=25 \mathrm{ml} \mathrm{min}^{-1}$ ) for several hours to the temperature of $1000^{\circ} \mathrm{C}$. At these conditions the macroscopic amounts of indium are entirely removed from the sample. The separation factor based on comparison of the activity of ${ }^{114 \mathrm{~m}} \mathrm{In}$ (indicator for macroamounts of indium) in the irradiated sample before and after heating can be estimated as $>10^{3}$. Subsequently, this pre-cleaned tin sample containing ${ }^{113} \mathrm{Sn}$ was placed into a tantalum tube and could be used directly in the experiments generating permanently fresh carrier-free ${ }^{113 \mathrm{~m}} \mathrm{In}$. This generator method turned out to be advantageous since after only one single purification the irradiated solid tin sample was ready for multiple thermochromatographic experiments.
For the experiments with oxidizing carrier gases the elemental tin sample was used without tantalum directly as a source.

\subsection{Thermosublimatography and thermochromatography experiments}

The thermosublimation experiments and the thermochromatography experiments were carried out in a similar manner.

The experimental set-up used both for the thermosublimatography and for the thermochromatography is schematically shown in Fig. 3. The empty chromatographic quartz column or the quartz column covered inside by a thin gold foil was located inside of a hermetically sealed Inconel ${ }^{\circledR}$ steel tube. The carrier gas inlet and outlet were connected by Swagelok ${ }^{\circledR}$ components. Such a system is effective to maintain high carrier gas purities during the experiment by excluding diffusion of oxygen and water into the mobile phase. Additionally, at the beginning of the column a Ta foil was placed acting as a getter for remaining traces of water and oxygen as this zone was heated up to $T=1000{ }^{\circ} \mathrm{C}$ prior to the experiment. The second Ta-getter was located downstream adjacent to the sample at about $980{ }^{\circ} \mathrm{C}$ to ensure the metallic state of ${ }^{113 \mathrm{~m}} \mathrm{In}$. The experiments with solid metallic tin as a sample have been performed using a gradient furnace from HTM Reetz GmbH with $T_{\max }=1300^{\circ} \mathrm{C}$, whereas in case of eluted ${ }^{113 \mathrm{~m}} \mathrm{In}$ the gradient furnace was self-made and started from $T=1000^{\circ} \mathrm{C}$ at otherwise similar experimental conditions. The experiments were performed as described by the following procedure:

- The ${ }^{113 \mathrm{~m}}$ In containing sample as obtained from the preparative steps described in Sect. 2.1 was positioned inside the start oven at the startup of the experiment;

- After the temperature gradient was established, this oven was heated up rapidly within about $5 \mathrm{~min}$ to $T=1000^{\circ} \mathrm{C}$. To investigate chemical properties of different indium species in several experiments various carrier gases and carrier gas mixtures were used.

- In case of oxidizing carrier gases the Ta getters were omitted and the tin metal was positioned in an alumina tube inside of the quartz column. This approach was needed because at oxidizing conditions the macroscopic amount of tin oxide was reacting with the quartz surface of the column, which leads to glass formation and a subsequent column failure.

- After the end of the experiment the column was removed from the temperature gradient oven through the cold end.

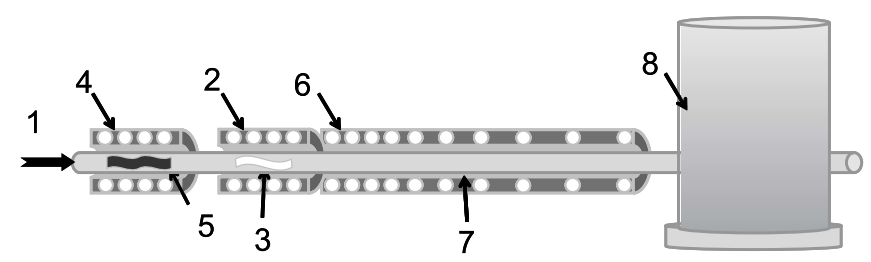

Fig. 3. Thermochromatography set-up. 1 - carrier gas $\left(\mathrm{Ar}, \mathrm{H}_{2}, \mathrm{O}_{2}\right.$ or mixtures with water $) ; 2-$ start oven $\left(1000 / 1300{ }^{\circ} \mathrm{C}\right) ; 3-{ }^{113 \mathrm{~m}} \mathrm{In}$ source either on a tantalum foil, or on a quartz wool surface, or inside of irradiated metallic tin in $\mathrm{Al}_{2} \mathrm{O}_{3} ; 4-$ getter oven $\left(1000^{\circ} \mathrm{C}\right) ; 5-\mathrm{Ta}$ chips; 6 - gradient oven; 7 - chromatographic column (quartz/gold), inner diameter $4 \mathrm{~mm}$; 8 - cooling system (up to liquid nitrogen $77 \mathrm{~K}$ temperature). 
Table 2. Experimental conditions.

\begin{tabular}{|c|c|c|c|c|c|c|}
\hline $\begin{array}{l}\text { Initial sample } \\
\text { description }\end{array}$ & $\begin{array}{l}\text { Carrier } \\
\text { gas }\end{array}$ & Column & $\begin{array}{c}\text { Flow } \\
\text { rate, } \\
\mathrm{ml} \mathrm{min}^{-1}\end{array}$ & $\begin{array}{l}\text { Experiment } \\
\text { duration, } \\
\text { min }\end{array}$ & $\begin{array}{c}\text { Starting } \\
\text { temperature, } \\
{ }^{\circ} \mathrm{C}\end{array}$ & $\begin{array}{l}\text { Most } \\
\text { probable } \\
\text { species }\end{array}$ \\
\hline \multicolumn{7}{|c|}{ Thermosublimation experiments } \\
\hline Sn-irradiated $/ \mathrm{Al}_{2} \mathrm{O}_{3}$ & $\mathrm{H}_{2}$ & Quartz & 15 & 120 & 1300 & $\mathrm{In}, \mathrm{InOH}, \mathrm{InO}$ \\
\hline $\mathrm{Sn}$-irradiated $/ \mathrm{Al}_{2} \mathrm{O}_{3}$ & $\mathrm{O}_{2}$ & Quartz & 25 & 120 & 1300 & $\mathrm{In}(\mathrm{OH})_{3}, \mathrm{In}_{2} \mathrm{O}_{3}$ \\
\hline Sn-irradiated $/ \mathrm{Al}_{2} \mathrm{O}_{3}$ & $\mathrm{O}_{2} / \mathrm{H}_{2} \mathrm{O}$ & Quartz & 25 & 120 & 1300 & $\mathrm{In}(\mathrm{OH})_{3}, \mathrm{In}_{2} \mathrm{O}_{3}$ \\
\hline In-eluted/Ta & Ar & Quartz & 50 & 60 & 1000 & $\mathrm{In}, \mathrm{InOH}, \mathrm{InO}$ \\
\hline \multicolumn{7}{|c|}{ Thermochromatographic experiments } \\
\hline In-eluted/Ta & $\mathrm{Ar}$ & Quartz & 50 & 60 & 1000 & $\mathrm{In}, \mathrm{InOH}, \mathrm{InO}$ \\
\hline In-eluted/Quartz Wool & $\mathrm{O}_{2}$ & Quartz & 50 & 60 & 1000 & $\mathrm{InOH}, \mathrm{InO}$ \\
\hline $\mathrm{Sn}$-irradiated $/ \mathrm{Al}_{2} \mathrm{O}_{3}$ & $\mathrm{H}_{2}$ & Quartz & 15 & 120 & 1300 & $\mathrm{In}, \mathrm{InOH}, \mathrm{InO}$ \\
\hline $\mathrm{Sn}$-irradiated $/ \mathrm{Al}_{2} \mathrm{O}_{3}$ & $\mathrm{O}_{2}$ & Quartz & 25 & 120 & 1300 & $\mathrm{InO}, \mathrm{In}(\mathrm{OH})_{3}$ \\
\hline Sn-irradiated $/ \mathrm{Al}_{2} \mathrm{O}_{3}$ & $\mathrm{O}_{2} / \mathrm{H}_{2} \mathrm{O}$ & Quartz & 25 & 120 & 1300 & $\mathrm{InO}, \mathrm{In}(\mathrm{OH})_{3}$ \\
\hline In-eluted/Ta & $\mathrm{Ar}$ & Gold & 50 & 60 & 1000 & $\mathrm{In}, \mathrm{InOH}$ \\
\hline
\end{tabular}

A screening of the activity distribution along the column was performed by a dose meter to roughly identify the position of the indium activity in the column. Subsequently these positions were measured by gamma spectroscopy using a lead collimator (window size $1 \times 1 \mathrm{~cm}^{2}$, lead thickness $0.7 \mathrm{~cm}$ ) in front of a standard HPGe- $\gamma$ detector with $2.13 \mathrm{keV}$ resolution at $1.33 \mathrm{MeV}$ in conjunction with an acquisition and analysis system based on Canberra's Genie $2 k^{\circledR}$.

All experiments with different carrier gases (see Table 2) were performed with macroamounts as well as with carrierfree amounts at otherwise the identical experimental conditions. The experiments with gold as stationary phase were performed only with carrier-free amounts of indium. Here, the gradient part of the column was entirely covered inside with rolled gold foils.

\section{Results and discussion}

\subsection{Experiments with inert and reducing carrier gas}

\subsubsection{Thermosublimatography}

Based on the scarcely available thermodynamic data (see Table 1) the expected chemical states of indium at the corresponding experimental conditions are indicated in Table 2.

The experiment performed with pure dry $\mathrm{H}_{2}$ as a carrier gas and starting from metallic tin results in deposition of carrier-added indium at $T_{\text {dep }}=945^{\circ} \mathrm{C}$ with $\Delta H_{\text {subl }}=360 \pm$ $20 \mathrm{~kJ} \mathrm{~mol}^{-1}$. This value is in good agreement with the value for the formation of the diatomic indium species $\mathrm{In}_{2}$ in the gas phase $\Delta H_{\text {subl }}\left(\mathrm{In}_{2}\right)=380 \mathrm{~kJ} \mathrm{~mol}^{-1}$ [26]. Therefore, we assume that at these conditions the metallic state is the most stable one.

Starting from the oxide form and using argon as a carrier gas the deposition of an indium species was observed at $350 \pm 20^{\circ} \mathrm{C}$. Using the thermosublimation model [19] from our experiments the sublimation enthalpy could be estimated as $\Delta H_{\text {subl }}=160 \pm 15 \mathrm{~kJ} \mathrm{~mol}^{-1}$. This observed deposition temperature is in reasonable agreement with the previously published data [17], where deposition temperatures of $T_{\text {dep }}=295 \pm 30^{\circ} \mathrm{C}$ are reported for macroscopic in- dium on quartz surfaces. This deposition peak was assigned to metallic monoatomic indium in [17]. However, the absence of an extensive drying system should be considered when evaluating the speciation of indium in these studies. The authors of [17] used $\mathrm{H}_{2} \mathrm{SO}_{4 \text { (conc) }}$ as a water catching substance and no other precautions in order to remove oxygen traces were made. At such experimental conditions the formation of $\mathrm{InOH}$ rather than metallic indium can be expected. Another argument is that in experiments performed at similar experimental conditions with carrier-added thallium [25] the formation of $\mathrm{TlOH}$ has been observed. An increase of the stability of $\mathrm{InOH}$ compared to $\mathrm{TlOH}$ is expected in comparison to the corresponding elemental states. Therefore, the low temperature deposition peak is tentatively attributed to indium monohydroxide. This presumption was confirmed during a validation procedure as described in Sect. 3.4.

\subsubsection{Thermochromatography}

A thermochromatogram of carrier-free indium in a quartz column using argon as a carrier gas and introducing samples prepared from the liquid phase separation process is shown in Fig. 4. The deposition temperatures $T_{\text {dep }}=320 \pm$ $10^{\circ} \mathrm{C}$ are in excellent agreement with the previously obtained $T_{\text {dep }}=330 \pm 30^{\circ} \mathrm{C}$ [17]. Using the Monte-Carlo simulation method [18] the enthalpy of adsorption was determined as $-\Delta H_{\mathrm{ads}}\left({ }^{113 \mathrm{~m}} \mathrm{InOH}\right)=143 \pm 10 \mathrm{~kJ} \mathrm{~mol}^{-1}$ (Fig. 4).

Using irradiated tin as a source of carrier-free ${ }^{113 \mathrm{~m}} \mathrm{In}$ and pure and dry hydrogen as a carrier gas as well as $1300^{\circ} \mathrm{C}$ starting temperature two different deposition temperatures were observed: $T_{1}=739 \pm 20^{\circ} \mathrm{C}$ and $T_{2}=250 \pm$ $20^{\circ} \mathrm{C}$ (Fig. 5). The second peak seems to originate from the same compound as shown in Fig. 4, whereas the first peak we attribute tentatively to a deposition of elemental indium. Using the Monte Carlo model [18] the adsorption enthalpy of carrier-free metallic ${ }^{113 \mathrm{~m}} \mathrm{In}$ on quartz was determined as $-227 \pm 10 \mathrm{~kJ} \mathrm{~mol}^{-1}$ (Fig. 5). This observation was confirmed in additional experiments. Using pure hydrogen as carrier gas ensures the low oxidation states for indium. Therefore, we prefer the determined adsorption enthalpy from this measurement for $\mathrm{InOH}$ on quartz surfaces $\left(-\Delta H_{\text {ads }}\left({ }^{113 \mathrm{~m}} \mathrm{InOH}\right)=124 \pm 10 \mathrm{~kJ} \mathrm{~mol}^{-1}\right)$. 


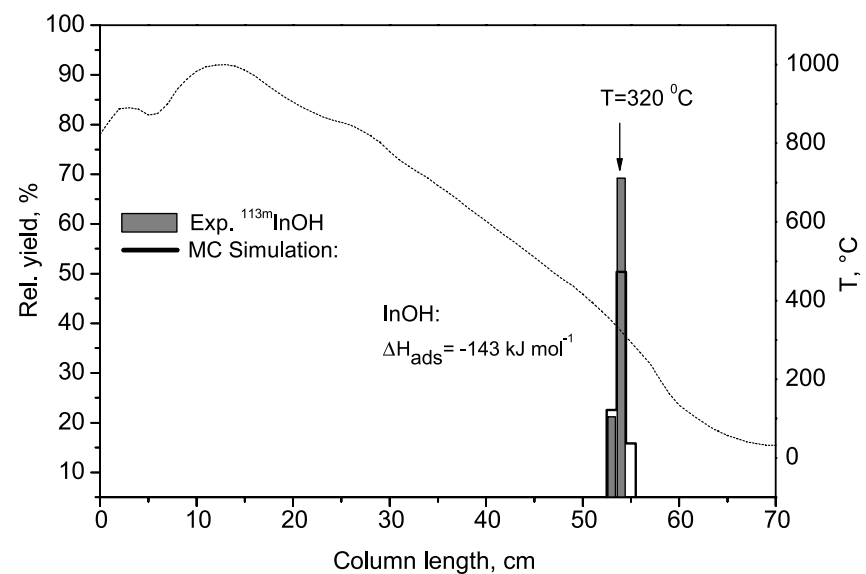

Fig. 4. Thermochromatogram of ${ }^{113 \mathrm{~m}} \mathrm{InOH}$ on quartz surface (grey bars, left hand axis) using as carrier gas $50 \mathrm{ml} \mathrm{min}^{-1}$ argon. The solid line indicates the result of the Monte-Carlo simulation of the expected deposition pattern for InOH with an adsorption enthalpy of $-143 \pm$ $10 \mathrm{~kJ} \mathrm{~mol}^{-1}$. The temperature gradient is shown (dashed line, right hand axis).

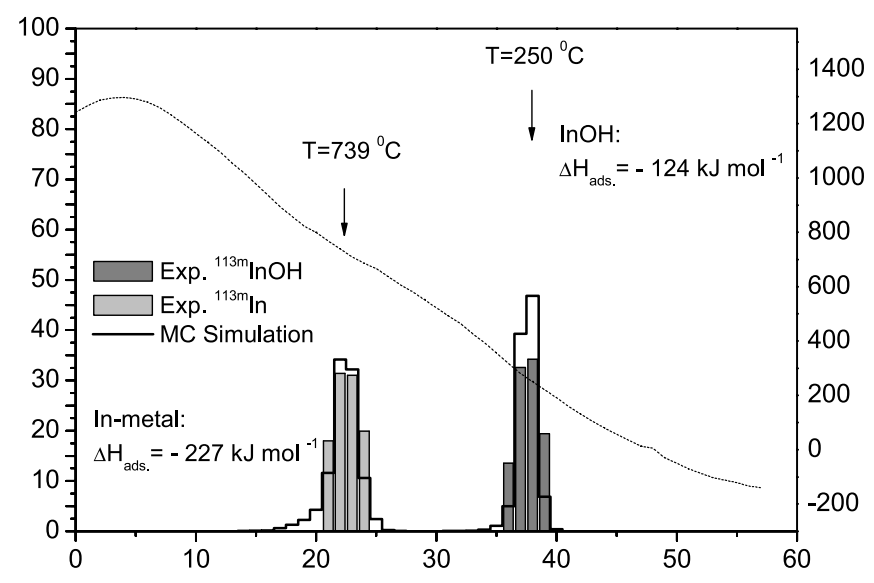

Fig. 5. Experimental thermochromatograms of carrier-free ${ }^{113 \mathrm{~m}} \mathrm{In}$ species on quartz surface (grey bars, left hand axis) using as carrier gas $15 \mathrm{ml} \mathrm{min}{ }^{-1} \mathrm{H}_{2}$. The solid line indicate the results of Monte-Carlo simulations of the expected deposition patterns for indium and $\mathrm{InOH}$ with an adsorption enthalpy of $-227 \pm 10 \mathrm{~kJ} \mathrm{~mol}^{-1}$ and $-124 \pm 10 \mathrm{~kJ} \mathrm{~mol}^{-1}$, respectively. The temperature gradient is shown (dashed line, right hand axis).

\subsection{Experiments with oxidizing carrier gas}

\subsubsection{Thermosublimatography and thermochromatography}

In the experiments with pure $\mathrm{O}_{2}$ and $\mathrm{O}_{2} / \mathrm{H}_{2} \mathrm{O}$ as carrier gases both carrier-added and carrier-free amounts of indium did not form any oxide or hydroxide species volatile either at $1000{ }^{\circ} \mathrm{C}$ from a quartz wool plug or from $\mathrm{Al}_{2} \mathrm{O}_{3}$ at $1300^{\circ} \mathrm{C}$ (see Table 2). This observation might be explained by a high reactivity of the oxide or oxohydroxide species of indium in its oxidation state three with quartz and alumina at the experimental conditions with a formation of non-volatile glasses. This behavior was not observed for thallium, whose oxidation state $3+$ is less stable that of indium [25]. Hence, we suggest that this approach could be an excellent tool for the preparative separation of indium from thallium. This observed difference between indium and thallium can also be applied to design a test experiment for the stability of the trivalent oxidation state of the elements of group 13, including the transactinide element 113.

\subsection{Thermochromatography of ${ }^{113 \mathrm{~m}}$ In in gold columns}

The thermochromatography experiments of indium on gold surfaces revealed that ${ }^{113 \mathrm{~m}} \mathrm{In}$ was entirely deposited on the first four centimeters of the gold surface, at $T_{\text {dep }}=980^{\circ} \mathrm{C}$. Due to the low melting point of gold, the gold coverage of the quartz column could be installed only at temperatures of about $980^{\circ} \mathrm{C}$ and lower. Hence, the observed deposition temperature was established as a lower limit deposition temperature of single atoms of ${ }^{113 \mathrm{~m}} \mathrm{In}$ on gold. A lower limit value for $-\Delta H_{\text {ads }}$ of single atomic indium on gold surfaces could be determined as $315 \pm 10 \mathrm{~kJ} \mathrm{~mol}^{-1}$ (Fig. 6). This value is in good agreement with data predicted by using the Eichler-Miedema adsorption model [28] $\left(-\Delta H_{\mathrm{ads}}^{\mathrm{Au}}(\mathrm{In})=313.8 \mathrm{~kJ} \mathrm{~mol}^{-1}\right)$.

\subsection{Validation of the presumed speciation}

To validate the suggested speciation of the observed indium depositions (In and $\mathrm{InOH}$ ) correlation plots between macroscopic $\left(\Delta H_{\text {subl }}\right)$ and microscopic $\left(\Delta H_{\text {ads }}\right)$ properties were used (see Figs. 7 and 8). The data obtained in our experiments for $\mathrm{InOH}$ are in reasonable agreement with the expectations, thus corroborating the assignment. The adsorption enthalpy of elemental indium on quartz is about $45 \mathrm{~kJ} \mathrm{~mol}^{-1}$ higher than the expected value from the correlation (see Fig. 7). This discrepancy might indicate a surface reaction involved in the chromatographic transport of elemental indium over quartz surfaces. However, the thermosublimation experiments clearly revealed the metallic state for indium at the corresponding experimental conditions. Further work is needed to resolve this problem. This unexpected effect shows even more the importance of such studies with the carrier-free amounts of the lighter elements of group 13 in preparation of the design of experiments with element 113.

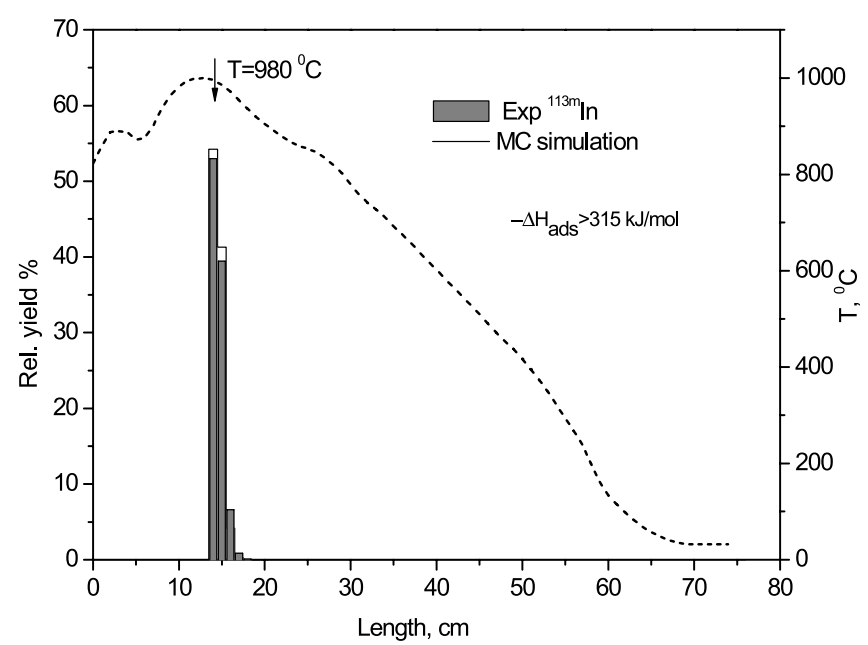

Fig. 6. Thermochromatogram of ${ }^{113 \mathrm{~m}} \mathrm{In}$ (grey bars, left hand axis) on gold surface using as carrier gas $50 \mathrm{ml} \mathrm{min}^{-1}$ argon. The solid line shows the result of the Monte-Carlo simulation of the expected deposition pattern for indium on gold with an adsorption enthalpy of $-315 \pm 10 \mathrm{~kJ} \mathrm{~mol}^{-1}$. The temperature gradient is shown (dashed line, right hand axis). 


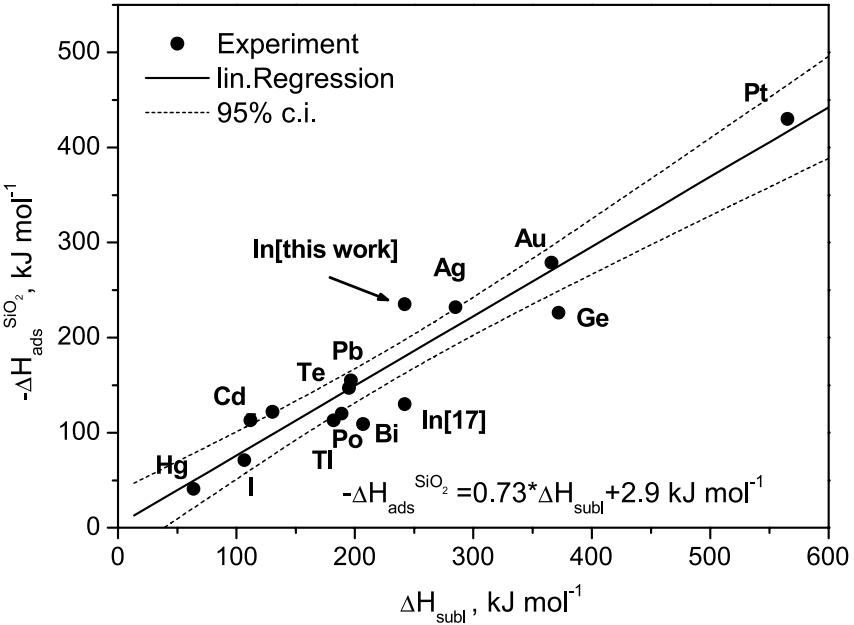

Fig. 7. Correlation of the adsorption enthalpy $\Delta H_{\text {ads }}$ of elements on quartz surfaces with the macroscopic property sublimation enthalpy $\Delta H_{\text {subl }}$ [22]. The value for indium obtained in this work is highlighted.

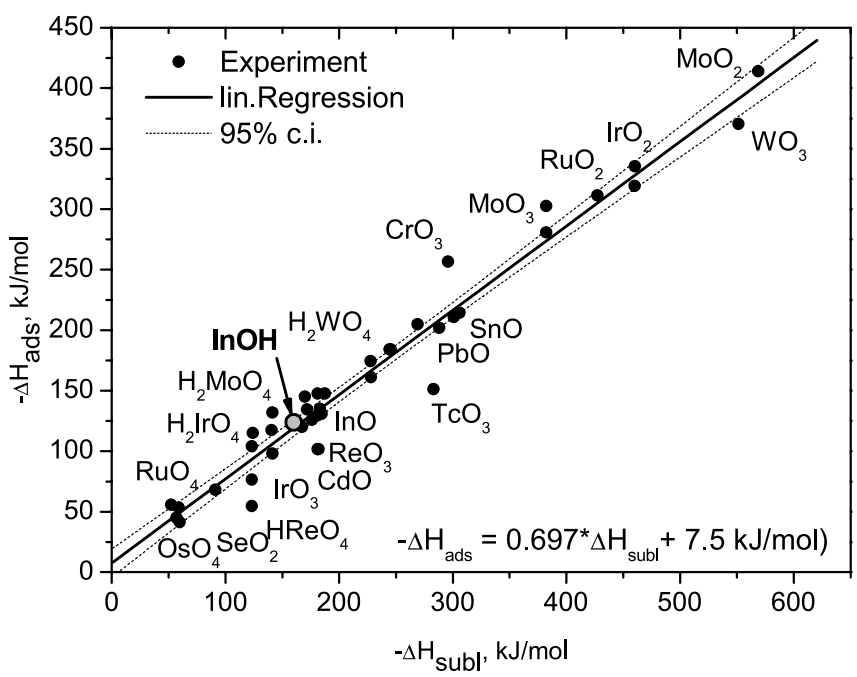

Fig. 8. Correlation of the adsorption enthalpy $\Delta H_{\text {ads }}$ of oxidic compounds on quartz surfaces with the macroscopic property sublimation enthalpy $\Delta H_{\text {subl }}$ [22]. The position of $\mathrm{InOH}$ within this correlation plot was obtained in this work.

\section{Conclusions}

Experiments with macroscopic amounts of indium revealed the deposition temperatures of $\mathrm{In}_{2}$ and $\mathrm{InOH}$. Sublimation data have been estimated for these species, $\Delta H_{\text {subl }}\left(\operatorname{In}_{2}\right)=$ $360 \pm 20 \mathrm{~kJ} \mathrm{~mol}^{-1}$ and $\Delta H_{\text {subl }}(\mathrm{InOH})=160 \pm 15 \mathrm{~kJ} \mathrm{~mol}^{-1}$. Data obtained for the sublimation enthalpy for $\mathrm{In}_{2}$ are in good agreement with the literature data [20]. Sublimation data for $\mathrm{InOH}$ have been deduced for the first time.

At carrier-free conditions it was observed that atomic indium is volatile revealing a deposition temperature on the quartz surface of $T_{\text {dep }}=739 \pm 20^{\circ} \mathrm{C}\left(-\Delta H_{\text {ads }}=227 \pm\right.$ $10 \mathrm{~kJ} \mathrm{~mol}^{-1}$ ) whereas InOH is deposited at $T=250 \pm 20^{\circ} \mathrm{C}$ $\left(-\Delta H_{\mathrm{ads}}=124 \pm 10 \mathrm{~kJ} \mathrm{~mol}^{-1}\right)$. The deposition of indium on gold surface indicates a much stronger interaction compared to quartz in good agreement with the prediction from [28]. A lower limit deposition temperature was established as $T_{\text {dep }}>980^{\circ} \mathrm{C}$, with a limit of adsorption enthalpy of $-\Delta H_{\mathrm{ads}}>315 \pm 10 \mathrm{~kJ} \mathrm{~mol}^{-1}$.
Based on deposition temperatures of the homologues of element 113 on quartz and on the gold surface from this work and for thallium from [25] it can be expected that E113 will reveal a lower deposition temperature in its elemental state compared to indium and thallium on both stationary surfaces, if the trend within the group 13 persists. The same trend should be expected in the case of deposition of the heavier group 13 monohydroxides on quartz surfaces [25]. Predictions obtained from quantum chemical calculations of E113 adsorption [27] corroborate these suggestions. An accurate prediction of the element 113 volatility in elemental state or as hydroxide remains difficult, though.

Acknowledgment. This work was supported by the Swiss National Science Foundation (grant: 200020-117671/1).

\section{References}

1. Oganessian, Yu. Ts.: Heaviest nuclei from ${ }^{48} \mathrm{Ca}$-induced reactions. J. Phys. G 34, R165-R242 (2007).

2. Schädel, M. (ed.): The Chemistry of Superheavy Elements. Kluwer Academic Publishers, Springer (2003).

3. Schädel, M.: Chemistry of superheavy elements. Angew. Chem. Int. Ed. 45, 368 (2006).

4. Zvara, I., Tschuburkov, Y. T., Zaletka, P., Zvarova, T. S., Shalaevski, M. R., Shilov, B. V.: Chemical properties of element 104. Atom. Energ. 21, 83 (1966).

5. Zvara, I., Chuburkov, Y. T., Caletka, R., Shalaevsky, M. R.: Chemical experiments with element 104. Sov. Radiochem. 11, 161 (1969), translated from Radiokhimiya 11, 163 (1969).

6. Kadkhodayan, B., Türler, A., Gregorich, K. E., Nurmia, M. J., Lee, D. M., Hoffman, D. C.: The heavy element volatility instrument (HEVI). Nucl. Instrum. Methods A 317, 254 (1992).

7. Kadkhodayan, B., Türler, A., Gregorich, K. E., Baisden, P. A., Czerwinski, K. R., Eichler, B., Gäggeler, H. W., Hamilton, T. M., Jost, D. T., Kacher, C. D., Kovacs, A., Kreek, S. A., Lane, M. R., Mohar, M. F., Neu, M. P., Stoyer, N. J., Sylwester, E. R., Lee, D. M., Nurmia, M. J., Seaborg, G. T., Hoffman, D. C.: On-line gas chromatographic studies of chlorides of rutherfordium and homologs Zr and Hf. Radiochim. Acta 72, 169 (1996).

8. Schädel, M., Brüchle, W., Dressler, R., Eichler, B., Gäggeler, H. W., Günther, R., Gregorich, K. E., Hoffman, D. C., Hübener, S., Jost, D. T., Kratz, J. V., Paulus, W., Schumann, D., Timokhin, S., Trautmann, N., Türler, A., Wirth, G., Yakushev, A.: Chemical properties of element 106 (seaborgium). Nature 388, 55 (1997).

9. Schädel, M., Brüchle, W., Schausten, B., Schimpf, E., Jäger, E., Wirth, G., Günther, R., Kratz, J. V., Paulus, W., Seibert, A., Thörle, P., Trautmann, N., Zauner, S., Schumann, D., Andrassy, M., Misiak, R., Gregorich, K. E., Hoffman, D. C., Lee, D. M., Sylwester, E. R., Nagama, Y., Oura, Y.: First aqueous chemistry with seaborgium (element 106). Radiochim. Acta 77, 149 (1997).

10. Türler, A., Brüchle, W., Dressler, R., Eichler, B., Eichler, R., Gäggeler, H. W., Gärtner, M., Glatz, J. P., Gregorich, K. E., Hübener, S., Jost, D. T., Lebedev, V. Ya., Pershina, V. G., Schädel, M., Taut, S., Timokhin, S. N., Trautmann, N., Yakushev, A. B.: First measurement of a thermochemical property of a seaborgium compound. Angew. Chem. Int. Ed. 38, 2212 (1999).

11. Eichler, R., Brüchle, W., Dressler, R., Düllmann, Ch. E., Eichler, B., Gäggeler, H. W., Gregorich, K. E., Hoffman, D. C., Hübener, S., Jost, D. T., Kirbach, U. W., Laue, C. A., Lavanchy, V. M., Nitsche, H., Patin, J. B., Piquet, D., Schädel, M., Shaughnessy, D. A., Strellis, D. A., Taut, S., Tobler, L., Tysganov, Y. S., Türler, A., Vahle, A., Wilk, P. A., Yakushev, A. B.: Chemical characterization of bohrium (element 107). Nature 407, 63 (2000).

12. Düllmann, Ch. E., Dressler, R., Eichler, B., Gäggeler, H. W., Glaus, F., Jost, D. T., Piguet, D., Soverna, S., Türler, A., Brüchle, W., Eichler, R., Jäger, E., Pershina, V., Schädel, M., Schausten, B., Schimpf, E., Schött, H.-J., Wirth, G., Eberhardt, K., Thörle, P., Trautmann, N., Ginter, T. N., Gregorich, K. E., Hoffman, D. C., Kirbach, U. W., Lee, D. M., Nitsche, H., Patin, J. B., Sudowe, R., Zielinski, P. M., Timokhin, S. N., Yakushev, A. B., Vahle, A., 
Qin, Z.: Chemical investigation of hassium (element 108). Nature 418, 859-862 (2002).

13. Eichler, R., Aksenov, N. V., Belozerov, A. V., Bozhikov, G. A., Chepigin, V. I., Dressler, R., Dmitriev, S. N., Gäggeler, H. G., Gorshkov, V. A., Haenssler, F., Itkis, M. G., Lebedev, V. Y., Laube, A., Malyshev, O. N., Oganessian, Yu. Ts., Petruschkin, O. V., Piguet, D., Rasmussen, P., Shishkin, S. V., Shutov, A. V., Svirikhin, A. I., Tereshatov, E. E., Vostokin, G. K., Wegrzecki, M., Yeremin, A. V.: Chemical properties of element 112 . Nature 447, 72-75 (2007).

14. Eichler, R., Aksenov, N.V, Belozerov, A. V., Bozhikov, G. A., Chepigin, V. I., Dressler, R., Dmitriev, S. N., Gäggeler, H. G., Gorshkov, V. A., Haenssler, F., Itkis, M. G., Lebedev, V. Y., Laube, A., Malyshev, O. N., Oganessian, Yu. Ts., Petruschkin, O. V., Piguet, D., Rasmussen, P., Serov, A. A., Shishkin, S. V., Shutov, A. V., Svirikhin, A. I., Tereshatov, E. E., Vostokin, G. K., Wegrzecki, M., Yeremin, A. V.: Thermochemical and physical properties of element 112. Angew. Chem. Int. Ed. 47(17), 3262-3266 (2008)

15. Wittwer, D., Abdullin, F. Sh., Aksenov, N. V., Albin, Yu. V., Bozhikov, G. A., Dmitriev, S. N., Dressler, R., Eichler, R., Gäggeler, H. W., Henderson, R. A., Hübener, S., Kenneally, J. M., Lebedev, V. Ya., Lobanov, Yu. V., Moody, K. J., Oganessian, Yu. Ts., Petrushkin, O. V., Polyakov, A. N., Piguet, D., Rasmussen, P., Sagaidak, R. N., Serov, A., Shirokovsky, I. V., Shaughnessy, D. A., Shishkin, S. V., Sukhov, A. M., Stoyer, M. A., Stoyer, N. J., Tereshatov, E. E., Tsyganov, Yu. S., Utyonkov, V. K., Vostokin, G. K., Wegrzecki, M., Wilk, P. A.: Gas phase chemical studies of superheavy elements using the dubna gas-filled recoil separatorstopping range determination. Nucl. Instrum. Methods B 268(1), 28 (2010).

16. Eichler, R., Aksenov, N. V., Albin, Yu. V., Belozerov, A. V., Bozhikov, G. A., Chepigin, V. I., Dmitriev, S. N., Dressler, R., Gäggeler, H. W., Gorshkov, V. A., Henderson, R. A., Johnsen, A. M., Kenneally, J. M., Lebedev, V. Ya., Malyshev, O. N., Moody, K. J., Oganessian, Yu. Ts., Petrushkin, O. V., Piguet, D., Popeko, A. G., Rasmussen, P., Serov, A., Shaughnessy, D. A., Shishkin, S. V., Shutov, A. V., Stoyer, M. A., Stoyer, N. J., Svirikhin, A. I., Tereshatov, E. E., Vostokin, G. K., Wegrzecki, M., Wilk, P. A., Witt- wer, D., Yeremin, A. V.: Indication for a volatile element 114. Radiochim. Acta 38, 133-139 (2010).

17. Eichler, B.: Investigation of distribution of nuclear reaction products in carrier-free form by thermochromatography method in the hydrogen stream. Dubna Report P12-6662, 3 (1972).

18. Zvara, I.: Simulation of thermochromatographic processes by the Monte Carlo method. Radiochim. Acta 38, 95 (1985).

19. Eichler, B., Zude, F., Fan, W., Trautmann, N., Herrmann, G.: Volatilization and deposition of ruthenium oxides in a temperature gradient tube. Radiochim. Acta 56, 133 (1992).

20. Online database "Thermo-constants for elements and substances", http://www.chem.msu.su/cgi-bin/tkv.pl?show=welcome.html, in Russian (2010).

21. Barin, I., Knacke, O.: Thermochemical Properties of Inorganic Substances. Springer, New York (1973).

22. Barin, I.: Thermochemical Data of Pure Substances. $3^{\text {rd }}$ Edn., VCH-Verlagsgesellschaft, Weinheim (1995).

23. Skulan, A. J., Nielsen, I. M. B., Melius, C. F., Allendorf, M. D.: BAC-MP4 predictions of thermochemistry for gas-phase indium compounds in the In-H-C-O-Cl system. J. Phys. Chem. A 110, 281 (2006).

24. Adape, M. H., Potchen, E. J.: A simplified method for laboratory preparation of organ specific indium $113 \mathrm{~m}$ compounds. Korean J. Nucl. Med.. 3(1), 13 (1969).

25. König, S., Gäggeler, H. W., Eichler, R., Haenssler, F., Soverna, S.: The production of long-lived thallium isotopes and their thermochromatographic studies on quartz and gold. In: PSI Annual Report 2005, (2005).

26. Wagman, D. D., Evans, W. H., Parker, V. B., Hallow, I., Bailey, S. M., Schumm, R. H.: Selected Values of Chemical Thermodynamic Properties National Bureau of Standards, Technical Notes No 270-1(1965), Ks 270-2(1966), Ns 270-3(1968), Ns 2704(1969), Washington, USA.

27. Pershina, V., Anton, J., Jacob, T.: Electronic structures and properties of $\mathrm{MAu}$ and $\mathrm{MOH}$, where $\mathrm{M}=\mathrm{Tl}$ and element 113 . Chem. Phys. Lett. 480, 157 (2009).

28. Eichler, B.: Adsorption of Metals on Metal Surfaces and the Possibility of its Application in Nuclear Chemistry. Report Zfk-396, Rossendorf (1979). 